\title{
International Workshop on Cybersafety Chairs' Welcome
}

It is our great pleasure to welcome you to the WWW 2018 Workshop on Computational Methods in Cybersafety, Online Harassment, and Misinformation. The theme of cybersafety is an important emerging research topic on the Internet that manifests itself daily as users navigate the Web and networked applications. After two successful workshops on cybersafety, the main goal of this third edition of this workshop on cybersafety is to build and grow the cybersafety research community by bringing together the leading researchers and practitioners from academia, industry, government, and research labs working in the general area of cybersafety to discuss the unique challenges in addressing various cybersafety issues and to share experiences, solutions, tools, and techniques. The focus is on the detection, prevention, and mitigation of various cybersafety issues, as well as education and promoting safe practices.

The focus of this workshop is on computational methods in cybersafety, including new algorithms, tools, data mining techniques, analysis, systems, and applications for the detection, prevention and mitigation of various cybersafety issues, as well as education and promoting safe practices. Our program features two invited keynote speakers. We will have Dr. April Edwards, Vice President for Academic Affairs and Dean of the Faculty at Elmhurst College, speak about Racial and Gender Differences in Cyberbullying Behavior. And we will have Dr. Neil Shah, Research Scientist at Snap Inc., speak about Anomaly Detection on Large Social Graphs. We will also feature four contributed presentations and publications selected from papers submitted to our workshop.

$\begin{array}{ll}\text { Richard Han } & \text { Jeremy Blackburn } \\ \text { Organizing Chair } & \text { Organizing Chair } \\ \text { University of Colorado, } & \text { University of Alabama at } \\ \text { Boulder } & \text { Birmingham } \\ \text { Homa Hosseinmardi } & \text { Qin Lv } \\ \text { Organizing Chair } & \text { Organizing Chair } \\ \text { University of Southern } & \text { University of Colorado, } \\ \text { California } & \text { Boulder } \\ \text { Bert Huang } & \text { Shivalkant Mishra } \\ \text { Program Chair } & \text { Program Chair } \\ \text { Virginia Tech } & \text { University of Colorado, } \\ & \text { Boulder }\end{array}$




\section{International Workshop on Cybersafety Organization}

Program Chairs: Bert Huang (Virginia Tech, USA)

Shivakant Mishra (University of Colorado, Boulder, USA)

Organizing Committee: Richard Han (University of Colorado, Boulder, USA)

Jeremy Blackburn (University of Alabama at Birmingham, USA)

Homa Hosseinmardi (University of Southern California, USA)

Qin Lv (University of Colorado, Boulder, USA)

Program Committee: Emiliano De Cristofaro (University College London, UK)

April Edwards (Elmhurst College, USA)

Jennifer Golbeck (University of Maryland, College Park, USA)

Nicolas Kourtellis (Telefonica Research)

Haewoon Kwak (Qatar Computing Research Institute)

Ilias Leontiadis (Telefonica Research)

Elaheh Raisi (Virginia Tech, USA)

Zubair Shafiq (The University of Iowa, USA)

Vivek Singh (Rutgers University, USA)

Michael Sirivianos (Cyprus University of Technology, Cyprus)

Francesca Spezzano (Boise State University, USA)

Gianluca Stringhini (University College London, UK)

Matteo Varvello (AT\&T Labs-Research) 